\title{
Analysis of micro-holes shape in a textile terminal using optical microscopy
}

\author{
Vera Agafonova ${ }^{1, *}$ \\ ${ }^{1}$ Moscow State University of Civil Engineering, Yaroslavskoye shosse, 26, 129337, Moscow, Russia
}

\begin{abstract}
Currently, development and improvement of ventilation and air conditioning systems efficiency is related with the use of new devices for air transportation and distribution. These include micro perforated air distributors made of textile which are installed both at the level of the indoor working area and directly near the workplace. Air terminals of this type are made of polymer composite material - fabric based on synthetic fibers. To make such a fabric, modern laser technology to produce microholes is used which allows burning in the fabric holes of a given diameter and pitch with melted edges. Results of studies on shape and size of microholes in the micro perforated textile terminal are described in this paper. A conclusion is made that the micro-holes shape is irregular and the holes boundaries have uneven edges. Data on micro-holes area range are given. Actual diameter of the micro-holes declared by manufacturer is defined more exactly.
\end{abstract}

\section{Introduction}

Air quality is the most important indicator of the indoor working area microclimate which affecting productivity, well-being and individual comfort of a person [1-8]. Development of modern technologies is closely related with the use of new technologies and materials for air terminals production. One of the technologies is production of micro perforated textile terminals using polymer composite material - fabrics based on synthetic fibers. Modern laser technologies allow burning holes in textile material with a given pitch and diameter. The micro-holes diameter is $0.2-0.6 \mathrm{~mm}$.

One of the advantages of the micro perforated textile terminal is possibility to supply air in the form of micro-jets with a small velocity directly into the human breathing zone [9]. Low air velocities in the breathing zone contribute to improving health of a person in the room and forming the required microclimate parameters and specified gas regime, taking into account variative external and internal factors [10-11].

Analysis of the works carried our by number of authors [12-15] leads to the conclusion that there are attempts to experimentally and theoretically study air distribution caused by textile air terminals, but the question remains unexplored concerning supply of air to the premises by means of textile terminals through micro holes.

\footnotetext{
* Corresponding author agafonovavv@ mgsu.ru
} 


\section{Experimental}

\subsection{Materials and experimental procedure}

The object of the study is an area of micro perforated textile terminal (Fig. 1) made of PMI fabric (100\% polyester, continuous fiber). In order to study shape and size of micro-holes made with a laser in the fabric of a textile terminal, microscopic analysis was carried out, with participation of the Scientific and Educational Center "Nanomaterials and Nanotechnology" of Moscow University of civil engineering (MGSU), using SENTERRA dispersion Raman spectrometer combined with optical microscope (Fig. 2). Declared by the manufacturer diameter of micro-hole is $0.2 \mathrm{~mm}$.

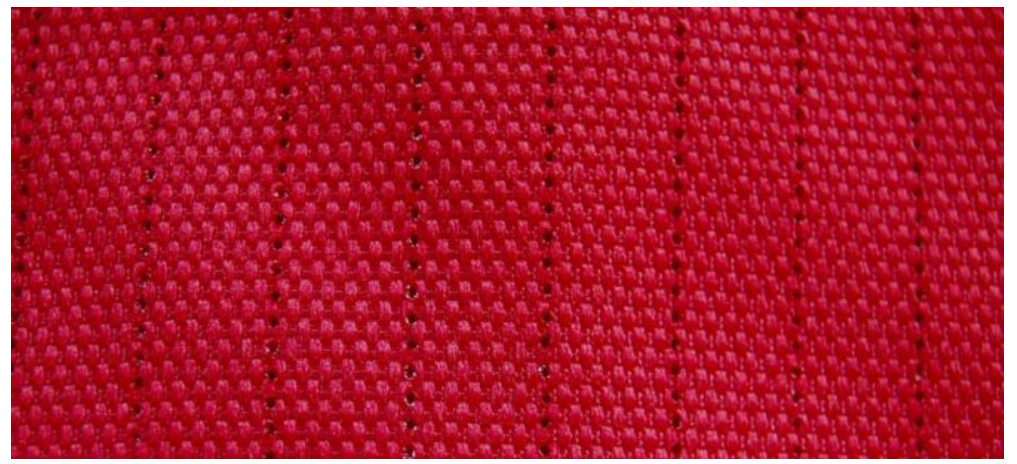

Fig. 1. Section of textile terminal with micro-holes

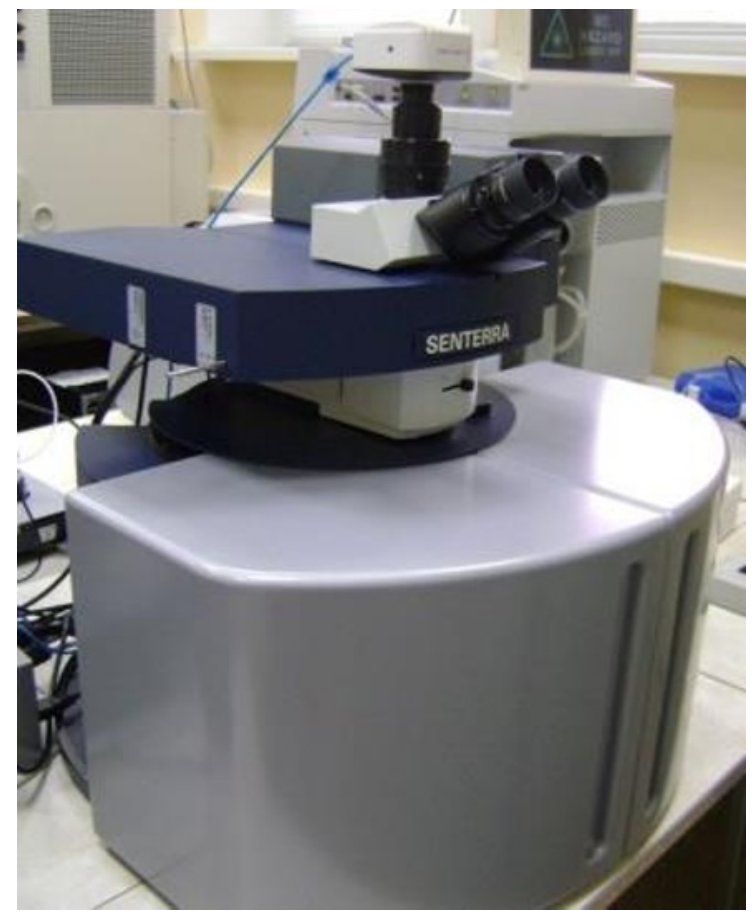

Fig. 2. SENTERRA dispersion Raman spectrometer 


\section{Results and discussion}

Fig. 3 shows type of warp and weft threads interlacing of the polymer material used for textile terminals production.

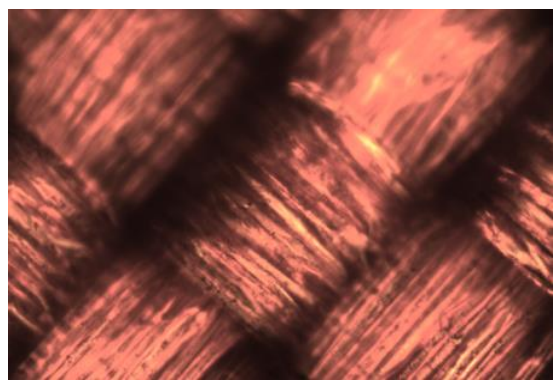

Fig. 3. Type of interlacing of textile terminal threads.

Microscopic analysis of the micro-holes located in one row of the investigated area of the textile terminal made it possible to conclude that the holes boundary has irregular edges, but the shape is more inclined to round. The micro-hole area $\left(\mathrm{S}, \mu \mathrm{m}^{2}\right)$ is not constant and varies in the range from $39629 \mu \mathrm{m}^{2}$ to $50955 \mu \mathrm{m}^{2}$, Table 1 .

Table 1. Area of micro-holes

\begin{tabular}{|c|c|c|c|c|c|c|c|c|c|c|}
\hline & \multicolumn{10}{|c|}{ Number of micro-holes } \\
\cline { 2 - 11 } & 1 & 2 & 3 & 4 & 5 & 6 & 7 & 8 & 9 & 10 \\
\hline $\begin{array}{c}\mathrm{S}, \\
\mu \mathrm{m}^{2}\end{array}$ & 48593 & 50955 & 48603 & 39629 & 41488 & 41700 & 45870 & 50238 & 43876 & 47718 \\
\hline
\end{tabular}

Micro-holes №2 and №4 (Table 1) with maximum and minimum areas are shown in Fig.4.

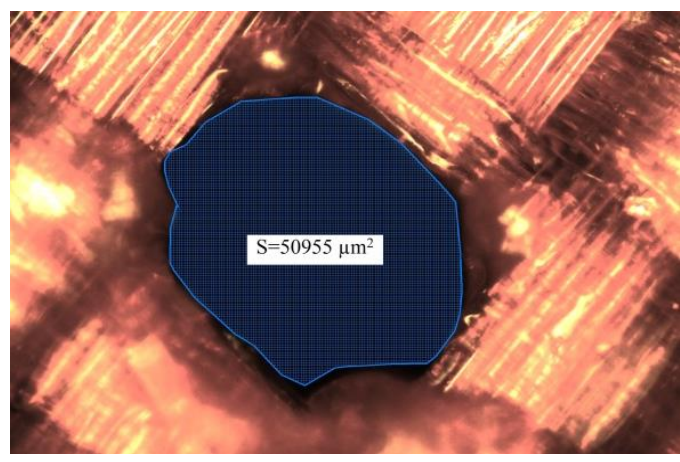

a

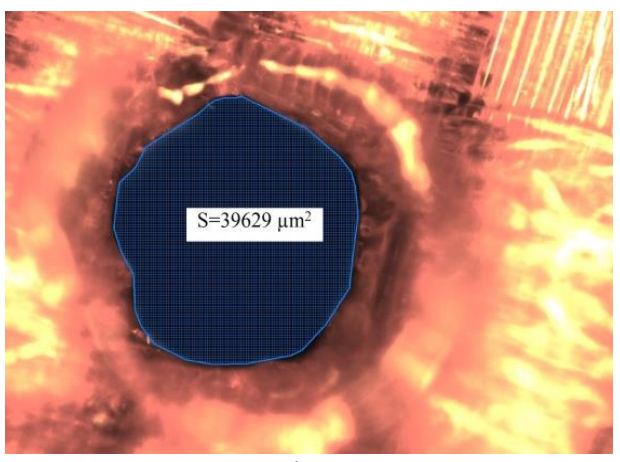

b

Fig. 4. Appearance of the holes: $a$ - hole №2 with maximum area, $b$ - hole №4 with minimum area

Also, diameter of a single fiber thread was investigated using SENTERRA optical microscope. Results of microscopic analysis are given in Table 2. Average diameter of a single fiber is $16.5 \mu \mathrm{m}$ (Fig. 4).

Table 2. Variation of the fiber thread diameter

\begin{tabular}{|c|c|c|c|c|c|c|c|c|c|c|}
\hline & \multicolumn{10}{|c|}{ Number of micro-holes } \\
\cline { 2 - 10 } & 1 & 2 & 3 & 4 & 5 & 6 & 7 & 8 & 9 & 10 \\
\hline $\begin{array}{c}\text { Fiber thread } \\
\text { diameter } \\
\mathrm{d}, \mu \mathrm{m}\end{array}$ & 16.8 & 17.1 & 17.1 & 16.7 & 16.5 & 16.1 & 16.7 & 16.1 & 15.7 & 16.0 \\
\hline
\end{tabular}




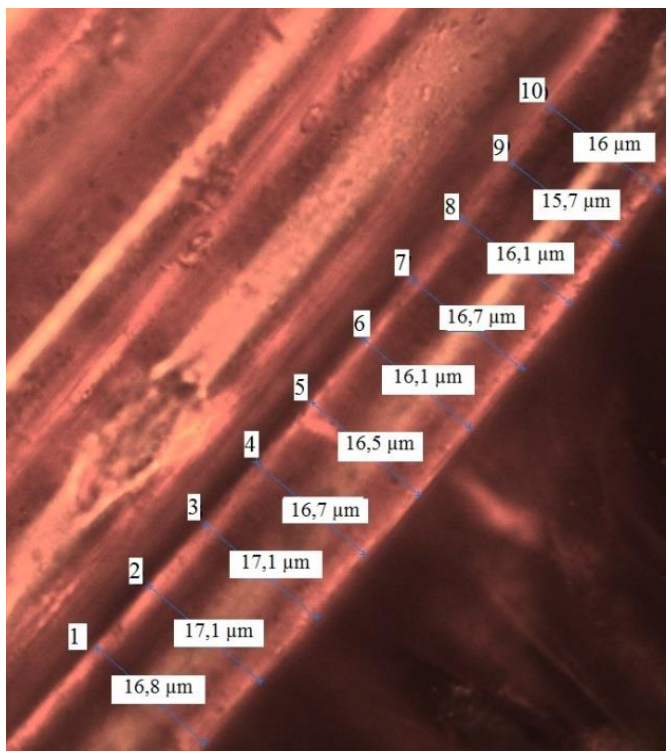

Fig. 5. Microstructure of textile terminal fiber.

\section{Conclusion}

The research carried out using optical microscopy method led to a conclusion that the micro-holes in the studied textile terminal are irregular and have rough edges. The hole area varies in the range from $50955 \mu \mathrm{m}^{2}$ to $39629 \mu \mathrm{m}^{2}$. Average micro-hole area is $\mathrm{S}=47718$ $\mu \mathrm{m}^{2}$ that corresponds to a diameter of $\mathrm{d}=242 \mu \mathrm{m}(0.24 \mathrm{~mm})$. Diameter of a single filament fiber varies from $16.0 \mu \mathrm{m}$ to $17.1 \mu \mathrm{m}$. These results were obtained to use in further research of the micro perforated textile terminal resistance.

\section{References}

1. A.G. Rymarov, Architecture and construction 5, 362 - 364 (2009)

2. A.G. Rymarov, Natural and technical sciences 6, 595 - 599 (2012)

3. A.G. Rymarov, Privolzhsky scientific journal 1(29), 61 - 63 (2014)

4. A.G. Rymarov, Bulletin of the MGSU Special issue \#2, 186 - 187 (2009)

5. E.P. Tolokonnikova, Management in biomedical systems 8. 4, 951-954 (2009)

6. L. Lagercrantz, Proceedings of Healthy Buildings 1, 653 - 658 (2000)

7. P. Wargocki, Proceedings of Healthy Buildings 1, 635-640 (2000)

8. P. Wargocki, Indoor Air, vol. 9 (3), 165-179 (2000)

9. A.G. Rymarov, V.V. Agafonova, Water supply and sanitary eng. 3, 60 - 63 (2018)

10. A.G. Rymarov, V.V. Agafonova, Privolzhsky scientific journal 1, 60 - 64 (2015)

11. A.G. Rymarov, V.V. Agafonova, Natural and technical sciences 2, 141 - 143 (2015)

12. P.V. Nielsen, C. Topp, et al. ASHRAE Transaction 8 (1), 733 - 739 (2005)

13. P.V. Nielsen, HVAC\&R Research 13 (4), 635-644 (2007)

14. C. Pinkalla, Construction Specifier 56 (6), 1-14 (2003).

15. F. Chen, H.Chen, J. Xie et al., Building and Environment 46 (11), 2121-2129 (2011) 